\title{
Rekomendasi Indekos dengan Metode Pembobotan pada Aplikasi E-Commerce CariKos Berbasis Web
}

\author{
Luwandino Wismar, R.V. Hari Ginardi, dan Sarwosri \\ Departemen Teknik Informatika, Fakultas Teknologi Informasi, Institut Teknologi Sepuluh Nopember \\ (ITS) \\ e-mail: hari@its.ac.id
}

\begin{abstract}
Abstrak-CariKos merupakan aplikasi $e$-commerce berbasis web yang dapat membantu dalam pencarian indekos. CariKos dapat membantu pemilik indekos memasarkan indekosnya. Selain itu, pencari indekos dapat mencari indekos sesuai dengan keinginannya dan melakukan transaksi pada aplikasi. Agar pencari mendapatkan indekos yang tepat, CariKos menyediakan fitur rekomedasi indekos menggunakan metode pembobotan. Metode pembobotan tersebut digunakan untuk mendapatkan nilai dari indekos. Nilai indekos didapatkan dari delapan nilai kriteria. Setiap kriteria memiliki nilai bobot persen masingmasing. Untuk mendapat bobot persen, digunakan Analytical Hierarchy Process. Tahap pengujian dilakukan dengan pendaftaran indekos dan pencarian indekos. Pencarian indekos dilakukan untuk melihat ketertarikan pengguna terhadap indekos yang direkomendasikan. Hasil pengujian menunjukkan bahwa 93.8\% partisipan tertarik dengan indekos yang direkomendasikan.
\end{abstract}

Kata Kunci-Analytical Hierarchy Process, Aplikasi Berbasis Web, Metode Pembobotan, Google Maps API, Pencarian Indekos.

\section{PENDAHULUAN}

$\mathrm{I}$ NDEKOS merupakan salah satu kebutuhan primer bagi mahasiswa, khususnya bagi mahasiswa perantau. Indekos dapat dikatakan sebagai tempat tinggal bagi mahasiswa selama menjalankan masa studinya.

Pada tahun 2017, Institut Teknologi Sepuluh Nopember (ITS) memiliki 19.969 mahasiswa [1]. Dengan jumlah tersebut, maka banyak dibangun indekos di sekitar ITS untuk menampung mahasiswa-mahasiswanya. Tahun 2017 ITS akan menampung 3.388 mahasiswa baru untuk jenjang S1 [2], dan mereka akan mulai melakukan pencarian indekos. Selain mahasiswa baru, pada saat yang bersamaan mahasiswa lama juga banyak yang kembali mencari indekos yang sesuai keiinginannya. Umumnya, saat ini pencarian indekos masih dilakukan dengan cara konvensional, yaitu dengan mengunjungi satu per satu indekos dan menanyakan ketersediaan kamar. Jika dilihat dengan banyaknya indekos yang berdiri di sekitar ITS, cara tersebut akan memerlukan waktu dan tenaga yang banyak untuk mendapatkan indekos yang sesuai. Untuk membantu para mahasiswa mencari indekos, dibangun sebuah aplikasi bernama CariKos.

CariKos memiliki fitur rekomendasi yang dapat memberikan mahasiswa indekos yang sesuai. Fitur tersebut menggunakan metode pembobotan untuk mendapatkan nilai dari setiap indekos. Nilai indekos berdasarkan dari beberapa kriteria. Beberapa kriteria menggunakan Google Maps API untuk mendapatkan jarak indekos dengan minimarket atau supermarket, jarak indekos dengan tempat ibadah, dan jarak indekos dengan gedung jurusan [3]. Selain itu, Google Maps API juga digunakan untuk melihat lokasi indekos pada daerah ramai dan daerah banjir. Sementara itu, beberapa kriteria lainnya berdasarkan dari informasi mengenai indekos tersebut yang dimasukkan oleh pemiliknya. Kriteria tersebut dapat berupa fasilitas kamar (kasur, meja, dan lemari), luas parkiran, dan ada atau tidaknya penjaga indekos.

Setiap kriteria memiliki bobot persen masing-masing yang didapatkan menggunakan Analytical Hierarchy Process. Selain itu, setiap kriteria juga memilki nilai-nilai parameternya. Nilai setiap kriteria berdasarkan nilai parameter dikalilkan dengan nilai bobot indekos.

\section{TINJAUAN PUSTAKA}

\section{A. Analytical Hierarchy Process}

Analitycal Hierarchy Process (AHP) adalah metode untuk memecahkan suatu situasi yang komplek tidak terstruktur ke dalam beberapa komponen dalam susunan yang hirarki, dengan memberi nilai subjektif tentang pentingnya setiap variabel secara relatif, dan menetapkan variabel mana yang memiliki prioritas paling tinggi guna memengaruhi hasil pada situasi tersebut.

Berikut situasi penentuan yang bisa menerapkan metode AHP [4]:

- Penentuan pemilihan

Pemilihan satu alternatif dari serangkaian alternatif yang ada, biasanya dimana ada beberapa kriteria keputusan yang terlibat.

- Penentuan urutan

Menempatkan satu set alternatif dari yang paling diinginkan sampai yang tidak diinginkan.

- Prioritisasi

Menentukan kelayakan relatif anggota dari satu set alternatif, berlawanan dengan memilih satu atau hanya memeringkatnya.

Adapun langkah-langkah metode AHP adalah [5]:

1. Menentukan kriteria-kriteria yang digunakan.

2. Menyusun kriteria-kriteria dalam bentuk matriks berpasangan. 
3. Memberikan nilai matriks, dengan cara:

i. Elemen $a[i, i]=1$ dimana $\mathrm{i}=1,2,3, \ldots, \mathrm{n}$

ii. Tabel 1 merupakan bobot elemen matriks segitiga atas

Tabel 1.

Bobot Elemen Matriks AHP

\begin{tabular}{ll}
\hline \hline Bobot & Deskripsi \\
\hline 1 & Kedua elemen seimbang \\
3 & Salah satu sedikit lebih penting \\
5 & Salah satu elemen lebih penting \\
7 & Salah satu elemen jelas lebih mutlak \\
9 & Salah satu elemen mutlak penting \\
$2,4,6,8$ & Nilai-nilai antara dua nilai pertimbangan- \\
& pertimbangan yang berdekatan \\
\hline \hline
\end{tabular}

iii. Elemen matriks segitiga bawah mempunyai rumus $a[j, i]=\frac{1}{a[i, j]}$ untuk $i \neq j$

\section{B. Google Maps API}

Google Maps adalah layanan aplikasi dan teknologi peta yang dikembangkan oleh Google. Google Maps API (Application Programming Interface) memungkinkan kita untuk menambahkan atau menyisipkan layanan peta Google Maps ke website. Google Maps API dapat disisipkan ke website menggunakan JavaScript.

Google Maps API menyediakan banyak fasilitas atau fitur yang dapat digunakan, antara lain:

\section{Distance Matrix}

Google Maps Distance Matrix adalah layanan yang menyediakan waktu dan jarak perjalanan untuk matriks tempat asal dan tujuan [6]. Google Maps Distance Matrix akan digunakan untuk mendapatkan jarak indekos terhadap minimarket, supermarket, tempat ibadah, dan lokasi jurusan.

\section{Places Library}

Berbagai fungsi di Google Places JavaScript Library memungkinkan aplikasi menelusuri tempat yang terdapat dalam area ditentukan [7]. Places Library digunakan untuk mendapatkan lokasi minimarket, supermarket dan tempat ibadah pada Google Maps.

3. Autocomplete

Pelengkapan otomatis (autocomplete) adalah fitur pustaka Places dalam Google Maps JavaScript API [8]. Autocomplete digunakan untuk pengguna mendapatkan alamat yang tersedia pada Google Maps.

\section{METODOLOGI}

\section{A. Menentukan Prioritas Kriteria}

Penyebaran kuesioner dilakukan untuk mendapatkan urutan prioritas dari kriteria dalam pemilihan indekos. Kuesioner diberikan kepada mahasiswa dan mahasiswi yang berjumlah enam puluh responden. Responden mengurutkan kriteria berdasarkan nilai prioritas, dengan nilai prioritas satu merupakan nilai tertinggi sampai nilai delapan yang terendah. Tabel 2 menunjukkan daftar kriteria. Tabel 3 menunjukkan daftar prioritas kriteria berdasarkan hasil kuesioner.

\section{B. Menghitung Bobot Persen Kriteria}

Dari hasil kuisioner didapatkan urutan prioritas dari masingmasing kriteria. Urutan prioritas tersebut selanjutnya akan digunakan untuk mencari bobot persen masing-masing kriteria menggunakan Analytical Hierarchy Process (AHP). Bobot persen akan digunakan dalam menentukan nilai indekos. Tabel 4 menunjukkan bobot persen dari masing-masing kriteria.

Tabel 2.

Daftar Kriteria

\begin{tabular}{ll}
\hline \hline Kriteria & Simbol \\
\hline Dekat dengan Supermarket/Minimarket & K1 \\
Dekat dengan Tempat Ibadah & K2 \\
Luas Parkiran & K3 \\
Terdapat Penjaga Indekos & K4 \\
Ketersediaan Fasilitas (Kasur, Meja, dan Lemari) & K5 \\
Tidak di Daerah Ramai & K6 \\
Tidak di Daerah Banjir & K7 \\
Dekat dengan Lokasi Jurusan & K8 \\
\hline \hline
\end{tabular}

Tabel 3.

Prioritas Kriteria

\begin{tabular}{ll}
\hline \hline Prioritas & Kriteria \\
\hline 1 & K5 \\
2 & K7 \\
3 & K1 \\
4 & K8 \\
5 & K3 \\
6 & K2 \\
7 & K6 \\
8 & K4 \\
\hline \hline
\end{tabular}

Tabel 4.

Bobot Persen Kriteria

\begin{tabular}{ll}
\hline \hline Kriteria & Bobot Persen \\
\hline K1 & $16 \%$ \\
K2 & $5 \%$ \\
K3 & $8 \%$ \\
K4 & $2 \%$ \\
K5 & $35 \%$ \\
K6 & $3 \%$ \\
K7 & $21 \%$ \\
K8 & $10 \%$ \\
\hline \hline
\end{tabular}

Tabel 5.

Nilai Parameter Kriteria

\begin{tabular}{lll}
\hline \hline Kriteria & Parameter & Nilai \\
\hline & $\leq 2 \mathrm{KM}$ & 100 \\
$\mathrm{~K} 1$ & $2 \mathrm{KM}<\mathrm{x} \leq 3 \mathrm{KM}$ & 75 \\
& $3 \mathrm{KM}<\mathrm{x} \leq 4 \mathrm{KM}$ & 50 \\
& $4 \mathrm{KM}<\mathrm{x} \leq 5 \mathrm{KM}$ & 25 \\
& $>5 \mathrm{KM}$ & 0 \\
& $\leq 2 \mathrm{KM}$ & 100 \\
$\mathrm{~K} 2$ & $2 \mathrm{KM}<\mathrm{x} \leq 3 \mathrm{KM}$ & 75 \\
& $3 \mathrm{KM}<\mathrm{x} \leq 4 \mathrm{KM}$ & 50 \\
& $4 \mathrm{KM}<\mathrm{x} \leq 5 \mathrm{KM}$ & 25 \\
& $>5 \mathrm{KM}$ & 0 \\
& $>15 \mathrm{Motor}$ & 100 \\
$\mathrm{~K} 3$ & $10 \mathrm{Motor}<\mathrm{x} \leq 15$ Motor & 75 \\
& $5 \mathrm{Motor}<\mathrm{x} \leq 10$ Motor & 50 \\
& $1 \mathrm{Motor} \leq \mathrm{x} \leq 5$ Motor & 25 \\
K4 & 0 & 0 \\
& Ya & 100 \\
K5 & Tidak & 0 \\
& Kasur + Meja + Lemari & 100 \\
& Kasur + Meja & 50 \\
\hline \hline
\end{tabular}




\begin{tabular}{lll}
\hline \hline & Tidak Ada & 0 \\
K6 & Ya & 100 \\
& Tidak & 0 \\
K7 & Ya & 100 \\
& Tidak & 0 \\
& $\leq 2 \mathrm{KM}$ & 100 \\
K8 & $2 \mathrm{KM}<\mathrm{x} \leq 3 \mathrm{KM}$ & 75 \\
& $3 \mathrm{KM}<\mathrm{x} \leq 4 \mathrm{KM}$ & 50 \\
& $4 \mathrm{KM}<\mathrm{x} \leq 5 \mathrm{KM}$ & 25 \\
& $>5 \mathrm{KM}$ & 0 \\
\hline \hline
\end{tabular}

\section{Menghitung Bobot Nilai Indekos}

Setiap kriteria mempunyai beberapa parameter yang dimana masing-masing parameter memiliki sebuah nilai. Nilai tersebut akan digunakan untuk menentukan nilai bobot dari kriteria. Tabel 5 menunjukkan nilai dari setiap parameter kriteria.

Kemudian, untuk mendapatkan nilai bobot dari indekos, menggunakan perhitungan:

$$
\begin{aligned}
& \mathrm{CV}=\mathrm{PV} \times \mathrm{PW} \% \\
& \mathrm{BV}=\sum \mathrm{CV}
\end{aligned}
$$

Dimana:

$\mathrm{NP}=$ Nilai Parameter

BK $=$ Bobot Kriteria

$\mathrm{NK}=$ Nilai Kriteria

NA = Nilai Akhir Indekos

\section{Menampilkan Rekomendasi Indekos}

Pada proses ini, aplikasi akan menampilkan rekomendasi indekos. Rekomendasi diambil dari empat indekos yang sesuai dengan kriteria dengan nilai bobot tertinggi.

\section{E. Uji Coba dan Evaluasi}

Proses terakhir adalah melakukan uji coba dan evaluasi. Uji coba dilakukan untuk menguji fitur-fitur pada aplikasi dan melihat ketertarikan pencari indekos terhadap indekos yang direkomendasikan. Kemudian, dilakukan pula evaluasi terhadap uji coba yang dilakukan.

\section{PERANCANGAN SISTEM}

Terdapat dua perancangan yang digunakan pada penelitian ini, yaitu pada modul pendaftaran indekos dan pencarian indekos. Gambar 1 menunjukkan perancangan pada modul pendaftaran indekos. Pada Gambar 1, proses dimulai dari pemilik indekos mendaftarkan indekos. Kemudian menggunakan latitude dan longitude dari alamat indekos, dilakukan pencarian dan perhitungan jarak indekos dengan minimarket, dilanjutkan dengan pencarian dan perhitungan jarak indekos dengan supermarket, dan kemudian pencarian dan perhitungan jarak indekos dengan tempat ibadah. Setelah itu, proses dilanjutkan dengan pengecekan lokasi indekos pada daerah banjir dan dilanjutkan ke proses perhitungan kriteria tujuh. Selanjutnya akan menuju proses pengecekan lokasi indekos pada daerah ramai dan dilanjutkan ke proses perhitungan kriteria enam. Apabila pemilik indekos ingin mendaftarkan kamar pada indekos, maka proses dilanjutkan ke proses pendaftaran kamar.

Gambar 2 menunjukkan perancangan pada modul pencarian indekos. Pada Gambar 2, proses dimulai dari pencari indekos mengisi kriteria pencarian indekos. Apabila pencari indekos ingin mencari indekos yang dekat dengan jurusan, maka proses dilanjutkan ke proses perhitungan jarak indekos ke jurusan dan perhitungan kriteria delapan. Selanjutnya, akan dilanjutkan ke proses perhitungan kriteria satu, perhitungan kriteria dua, perhitungan kriteria tiga, perhitungan kriteria empat, dan perhitungan kriteria lima. Setelah semua proses perhitungan dilakukan, pengguna akan diberikan rekomendasi indekos berdasarkan kriteria pencariannya.

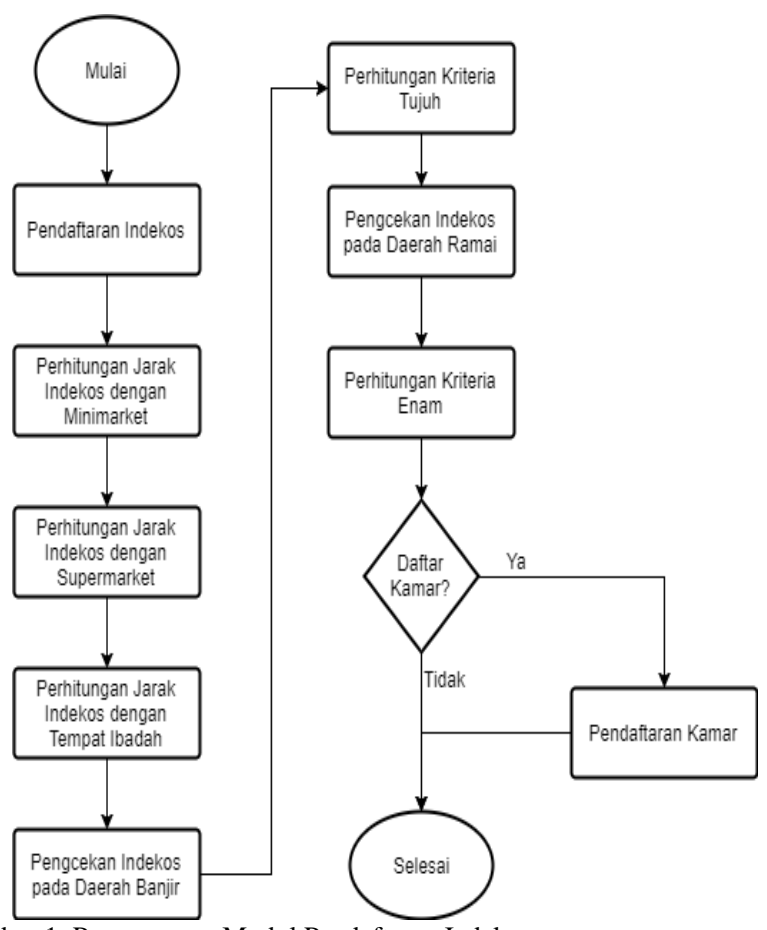

Gambar 1. Perancangan Modul Pendaftaran Indekos

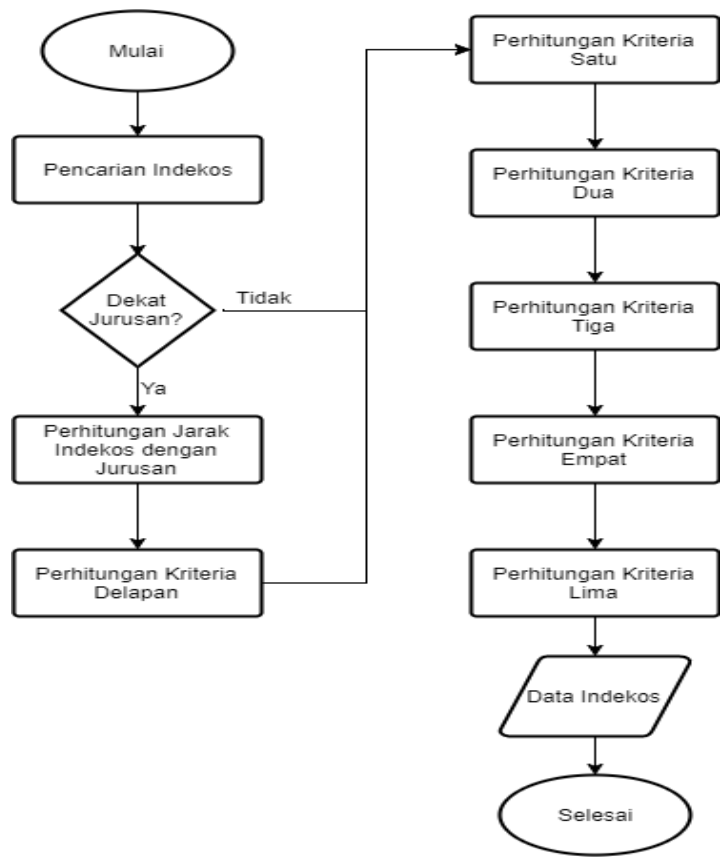

Gambar 2. Perancangan Modul Pencarian Indekos 


\section{PENGUJIAN DAN EVALUASI}

\section{A. Pengujian Nilai Bobot Indekos}

Pengujian ini dilakukan untuk melihat kebenaran perhitungan bobot indekos pada aplikasi. Perhitungan pada aplikasi akan dibandingkan dengan perhitungan secara manual. Tabel 6 menunjukkan perhitungan bobot indekos secara manual.

Tabel 7 menunjukkan hasil perhitungan bobot indekos pada aplikasi. Dari kedua hasil tersebut dapat dilihat bahwa kedua perhitungan memiliki nilai setiap kriteria dan nilai total yang sama. Maka, dapat disimpulkan bahwa perhitungan bobot indekos pada aplikasi sudah benar.

\section{B. Pengujian Ketertarikan Partisipan terhadap Aplikasi}

Pengujian ini dilakukan kepada 21 orang partisipan. Dimana lima orang partisipan sebagai pemilik indekos dan enam belas partisipan sebagai pencari indekos. Uji coba yang dilakukan partisipan meliputi fitur-fitur pada pengujian fungsional dan ketertarikan pencari indekos terhadap indekos yang direkomendasikan oleh aplikasi. Tabel 8 menunjukkan hasil kuesioner kepada pengguna pencari indekos dan Tabel 9 menunjukkan hasil kuesioner kepada pengguna pemilik indekos.

Tabel 6.

Perhitungan Manual Nilai Bobot Indekos

\begin{tabular}{|c|c|c|c|c|}
\hline Kriteria & $\begin{array}{c}\text { Data } \\
\text { Indekos }\end{array}$ & $\begin{array}{c}\text { Nilai } \\
\text { Parameter }\end{array}$ & $\begin{array}{l}\text { Bobot } \\
\text { Persen }\end{array}$ & $\begin{array}{c}\text { Nilai } \\
\text { Kriteria }\end{array}$ \\
\hline K1 & $0.961 \mathrm{KM}$ & 100 & $16 \%$ & 16 \\
\hline $\mathrm{K} 2$ & $0.63 \mathrm{KM}$ & 100 & $5 \%$ & 5 \\
\hline K3 & $\begin{array}{l}5 \text { Motor }<x \\
\leq 10 \text { Motor }\end{array}$ & 50 & $8 \%$ & 4 \\
\hline K4 & Tidak & 0 & $2 \%$ & 0 \\
\hline K5 & $\begin{array}{l}\text { Kasur, } \\
\text { Meja, dan } \\
\text { Lemari }\end{array}$ & 100 & $35 \%$ & 35 \\
\hline K6 & Ya & 100 & $3 \%$ & 3 \\
\hline K7 & Ya & 100 & $21 \%$ & 21 \\
\hline K8 & $0.71 \mathrm{KM}$ & 100 & $10 \%$ & 10 \\
\hline Total & & & & 94 \\
\hline
\end{tabular}

Tabel 7.

Perhitungan Nilai Bobot Indekos pada Aplikasi

\begin{tabular}{cc}
\hline \hline Kriteria & Nilai Kriteria \\
\hline K1 & 10 \\
K2 & 5 \\
K3 & 4 \\
K4 & 0 \\
K5 & 35 \\
K6 & 21 \\
K7 & 3 \\
K8 & 10 \\
\hline \hline
\end{tabular}

Tabel 8.

Kuesioner Pengguna Pencari Indekos

\begin{tabular}{lllll}
\hline \hline Pertanyaan & $\begin{array}{l}\text { Sangat } \\
\text { Setuju }\end{array}$ & Setuju & $\begin{array}{l}\text { Kurang } \\
\text { Setuju }\end{array}$ & $\begin{array}{l}\text { Tidak } \\
\text { Setuju }\end{array}$ \\
\hline $\begin{array}{l}\text { Apakah tampilan aplikasi } \\
\text { mempermudah dan } \\
\text { membuat Anda nyaman } \\
\text { dalam menggunakan }\end{array}$ & $43.8 \%$ & $50 \%$ & $6.2 \%$ & $0 \%$ \\
$\begin{array}{l}\text { aplikasi? } \\
\begin{array}{l}\text { Apakah aplikasi } \\
\text { memberikan kenyamanan }\end{array}\end{array}$ & $56.3 \%$ & $37.5 \%$ & $6.2 \%$ & $0 \%$ \\
\hline \hline
\end{tabular}

dan kemudahan saat melakukan pencarian indekos?

Apakah hasil pencarian

sesuai dengan kriteria yang

Anda masukkan?

Apakah informasi

mengenai indekos sudah

cukup lengkap?

Apakah Anda tertarik

dengan indekos yang

direkomendasikan?

Tabel 9.

Kuesioner Pengguna Pemilik Indekos

\begin{tabular}{lllll}
\hline \hline Pertanyaan & $\begin{array}{l}\text { Sangat } \\
\text { Setuju }\end{array}$ & Setuju & $\begin{array}{l}\text { Kurang } \\
\text { Setuju }\end{array}$ & $\begin{array}{l}\text { Tidak } \\
\text { Setuju }\end{array}$ \\
\hline $\begin{array}{l}\text { Apakah tampilan aplikasi } \\
\text { mempermudah dan } \\
\text { membuat Anda nyaman } \\
\text { dalam menggunakan }\end{array}$ & $20 \%$ & $60 \%$ & $20 \%$ & $0 \%$ \\
aplikasi? & & & & \\
$\begin{array}{l}\text { Apakah aplikasi } \\
\text { memberikan kenyamanan } \\
\text { dan kemudahan saat } \\
\text { melakukan pendaftaran }\end{array}$ & $20 \%$ & $60 \%$ & $20 \%$ & $0 \%$ \\
$\begin{array}{l}\text { indekos? } \\
\text { Apakah informasi yang } \\
\text { diminta mengenai indekos } \\
\text { sudah cukup lengkap? }\end{array}$ & $40 \%$ & $60 \%$ & $0 \%$ & $0 \%$ \\
$\begin{array}{l}\text { Apakah informasi yang } \\
\text { ditampilkan sesuai dengan } \\
\text { yang Anda masukkan? }\end{array}$ & $40 \%$ & $60 \%$ & $0 \%$ & $0 \%$ \\
\hline \hline
\end{tabular}

Berdasarkan hasil kuesioner pada Tabel 6 dan Tabel 7, dapat ditarik kesimpulan bahwa aplikasi ini dapat membantu partisipan dalam melakukan pencarian indekos. Hal ini dapat dilihat dari kuesioner bahwa 56.3\% dari partisipan sangat setuju bahwa dengan aplikasi ini dapat memberikan kemudahan dan kenyamanan untuk melakukan pencarian indekos. Selain itu, $43.8 \%$ partisipan sangat setuju dan $50 \%$ dari partisipan setuju bahwa partisipan tertarik dengan indekos yang direkomendasikan oleh aplikasi.

Dari sisi pemilik indekos, aplikasi ini juga sudah memberikan kenyamanan dan kemudahan dalam melakukan pendaftaran indekos. Hal tersebut dapat dilihat dari hasil kuesioner dimana $60 \%$ partisipan memilih setuju.

\section{KESIMPULAN}

Metode pembobotan mampu diimplementasikan untuk menentukan rekomendasi indekos pada aplikasi CariKos. Rekomendasi indekos yang diberikan sudah sesuai dengan kriteria pencarian. Aplikasi CariKos juga telah berhasil memberikan informasi yang cukup detail mengenai indekos yang direkomendasikan. Hasil dari pengujian ketertarikan partisipan terhadap aplikasi, menunjukkan bahwa 93.8\% partsipan tertarik dengan indekos yang direkomendasikan oleh aplikasi CariKos dan $6.2 \%$ kurang tertarik dengan indekos yang direkomendasikan. 


\section{DAFTAR PUSTAKA}

[1] "SRV4 PDDIKTI: Pangkalan Data Pendidikan Tinggi." [Daring]. Tersedia pada: https://forlap.ristekdikti.go.id/perguruantinggi. [Diakses: 07-Jul-2017].

[2] "SMITS - Seleksi Masuk ITS." [Daring]. Tersedia pada: http://smits.its.ac.id/sarjana/. [Diakses: 04-Jul-2017].

[3] I. W. Supriana, "Sistem Pendukung Keputusan dalam Pemilihan Tempat Kost dengan Metode Pembobotan (Studi Kasus: Sleman Yogyakarta)," J. Ilmu Komput., vol. 5, no. 2, Sep 2012.

[4] “Analytic Hierarchy Process," Wikipedia. 22-Mar-2017.

[5] "Metode Analytic Hierarchi Process dalam Penentuan Keputusan Pemilihan Tipe Rumah (Studi Kasus Di Perumahan Bukit Permata Puri Semarang)." [Daring]. Tersedia pada: http://www.dinus.ac.id/wbsc/assets/dokumen/majalah/METODE_ANA LYTIC_HIERARCHI_PROCESS_DALAM_PENENTUAN_KEPUTU
SAN_PEMILIHAN_TIPE_RUMAH_(STUDI_KASUS_DI_PERUMA HAN_BUKIT_PERMATA_PURI_SEMARANG).pdf. [Diakses: 16Mei-2017].

[6] "Layanan Distance Matrix | Google Maps JavaScript API," Google Developers. [Daring]. Tersedia pada: https://developers.google.com/maps/documentation/javascript/distance matrix?hl=id. [Diakses: 07-Jul-2017].

[7] "Places Library | Google Maps JavaScript API," Google Developers. [Daring]. Tersedia pada: https://developers.google.com/maps/documentation/javascript/places?hl =id. [Diakses: 07-Jul-2017].

[8] "Autocomplete untuk Alamat dan Istilah Penelusuran | Google Maps JavaScript API | Google Developers.” [Daring]. Tersedia pada: https://developers.google.com/maps/documentation/javascript/placesautocomplete. [Diakses: 07-Jul-2017]. 